\title{
PROVÁVEIS EFEITOS DAS MUDANÇAS CLIMÁTICAS GLOBAIS NO BALANÇO HÍDRICO CLIMATOLÓGICO DO ESTADO DE SANTA CATARINA - BRASIL
}

\author{
Aline de Freitas Roldão ${ }^{(a)}$; Patrícia Soares Rezende ${ }^{(b)}$; Vanderlei de Oliveira Ferreira ${ }^{(c)}$ \\ (a) Instituto de Geografia, Universidade Federal de Uberlândia, alineroldao@ yahoo.com.br \\ (b) Instituto de Geografia, Universidade Federal de Uberlândia, ps.rezende@ hotmail.com \\ (c) Instituto de Geografia, Universidade Federal de Uberlândia, vanderlei.ferreira@ufu.br
}

Eixo3. Climatologia em direfentes níveis escalares: Mudanças e Variabilidades

\begin{abstract}
Resumo
Esse estudo tem como objetivo simular efeitos das mudanças climáticas globais no balanço hídrico climatológico do estado de Santa Catarina. Inicialmente foi feito um levantamento dos dados meteorológicos disponíveis na área de estudo e selecionadas 13 estações, cujas informações estão disponíveis no banco de dados do Instituto Nacional de Meteorologia. Para calcular o balanço hídrico foi utilizada a metodologia de Thornthwaite e Mather (1955). Foi feito o balanço hídrico climatológico de todos os anos da série histórica compreendida entre 1961 e 1990. Em seguida, o mesmo procedimento foi repetido de acordo com as projeções estimadas pelo relatório do IPCC (2007) para o ano de 2080, portanto incluindo as alterações projetadas nos valores da temperatura e da precipitação pluviométrica. Foi possível verificar que em todas as estações meteorológicas adotadas haverá mudanças significativas no padrão de disponibilidade hídrica, com inevitáveis repercussões no zoneamento de culturas agrícolas e em atividades econômicas diversas.
\end{abstract}

Palavras chave: Mudanças Climáticas; Balanço Hídrico; Santa Catarina.

\section{Introdução}

As ações que estamos praticando no dia a dia, seja o aumento da emissão de carbono, desmatamento, queimadas, atividades industriais sem planejamento e controle, poluição dos cursos d'água, lixões e aterros sem o devido tratamento, contribuem para as mudanças climáticas e prejuízo para a saúde dos seres vivos. Para Nobre e Young (2011) a mudança climática acarretará muitas transformações nos aspectos da vida social no século XXI, seja em áreas urbanas ou rurais. Sendo assim é necessário elaborar estratégias para enfrentá-las.

Frente às mudanças climáticas, surge a necessidade de analisar como o aumento da temperatura e as alterações no padrão de precipitação pluviométrica podem alterar a disponibilidade hídrica de um determinado local. Daí a ideia de avaliar o balanço hídrico climatológico em cenários de mudanças climáticas. 


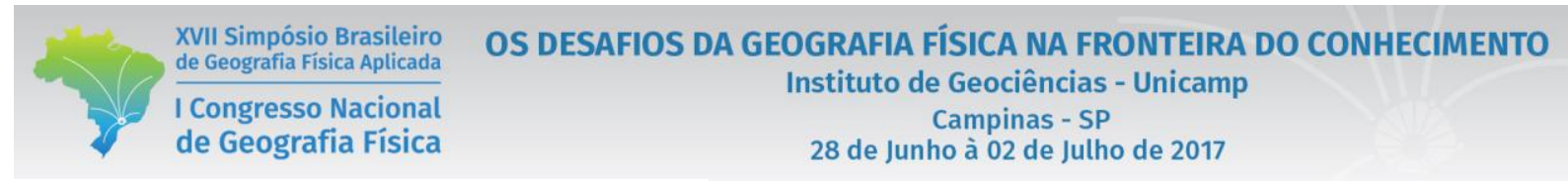

O cálculo do balanço hídrico climatológico "Consiste em contabilizar a evapotranspiração contra a precipitação, considerando-se uma determinada capacidade de armazenamento de água no solo, de forma a determinar a disponibilidade de água às culturas, nas diferentes épocas do ano e a melhor estação de cultivo para uma determinada região". (ANGIOLELLA E SILVA, [200-], p.01). Com as informações do balanço hídrico é possível acompanhar a disponibilidade hídrica de uma região e assim zonear qual tipo de cultura que se enquadra nas condições climáticas e hídricas da área.

O presente texto avalia mudanças no balanço hídrico diante de cenários de mudanças climáticas no estado de Santa Catarina, localizado na região sul do Brasil e composto por 295 municípios, conforme mostrado na Figura 1. Em 2015 o estado tinha uma população de 6.819 .190 pessoas. Sua área territorial é de $95.733,978 \mathrm{~km}^{2}$ (IBGE, 2016).

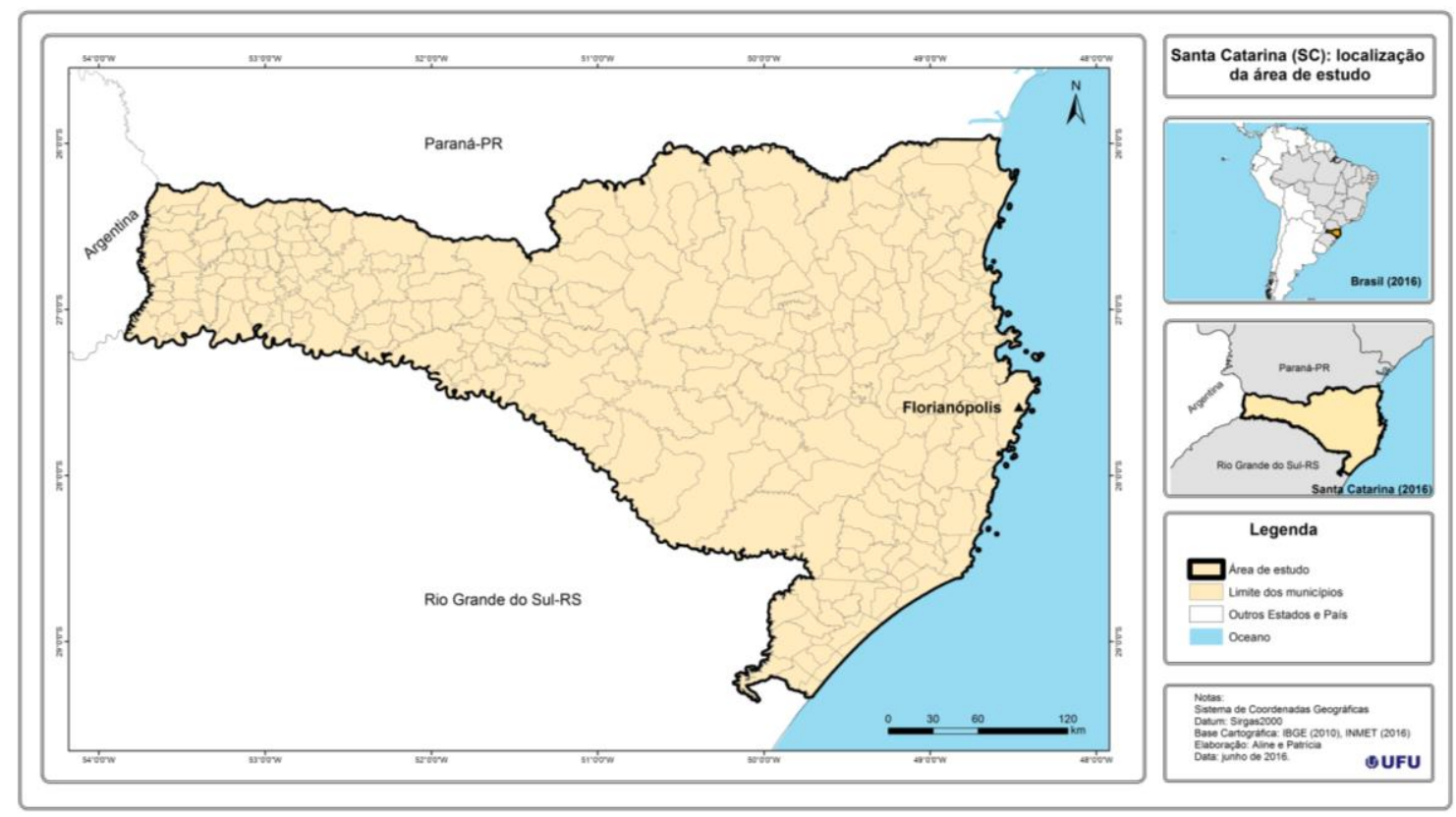

Figura 1 - Localização da área de estudo Elaboração: autores, 2016.

Sendo assim, esse estudo tem como objetivo analisar os impactos das mudanças climáticas no balanço hídrico climatológico do estado de Santa Catarina. E para atingir o objetivo proposto, foi necessário percorrer os seguintes objetivos específicos: a) Elaborar o balanço hídrico para o intervalo de 1961 a 1990; b) Entender o cenário futuro para um aumento de $4^{\circ} \mathrm{C}$ ao longo de todos os meses do ano e aumento de 5\% em relação à precipitação pluviométrica no trimestre (dezembro, janeiro e fevereiro) e uma diminuição de $10 \%$ para o trimestre (junho, julho e agosto). São cenários possíveis, dentro das possibilidades apontadas pelo IPCC (2007). 


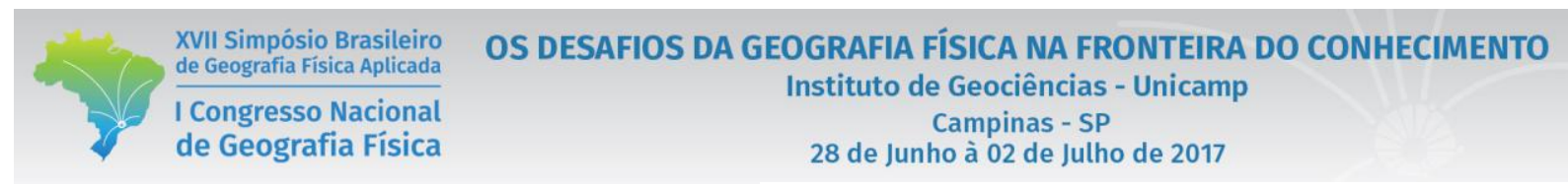

Abordagem similar foi testada por Ferreira, V. O; Silva, G. A; Silva, R. E e Frasson, V. M (2015) para a bacia do rio Grande, mediante estimativa da evapotranspiração por meio da equação de Penman-Monteith. Os resultados revelaram que, embora seja possível um aumento da precipitação na estação chuvosa, a queda da umidade relativa do ar e o aumento da temperatura poderão causar elevação da deficiência hídrica naquela importante bacia, criando a necessidade de adaptação e revisão das estratégias de utilização dos recursos hídricos pela agricultura, produção energética e segurança das populações envolvidas.

\section{METODOLOGIA}

Para a realização desse trabalho, inicialmente foi feito um levantamento das estações meteorológicas do estado de Santa Catarina cujas informações estão disponíveis no banco de dados do Instituto Nacional de Meteorologia (INMET). Foram selecionadas 13 dentre elas, conforme disposto na Figura 2. Optou-se utilizar os dados das estações que apresentam disponibilidade de séries históricas de melhor qualidade e mais extensas.

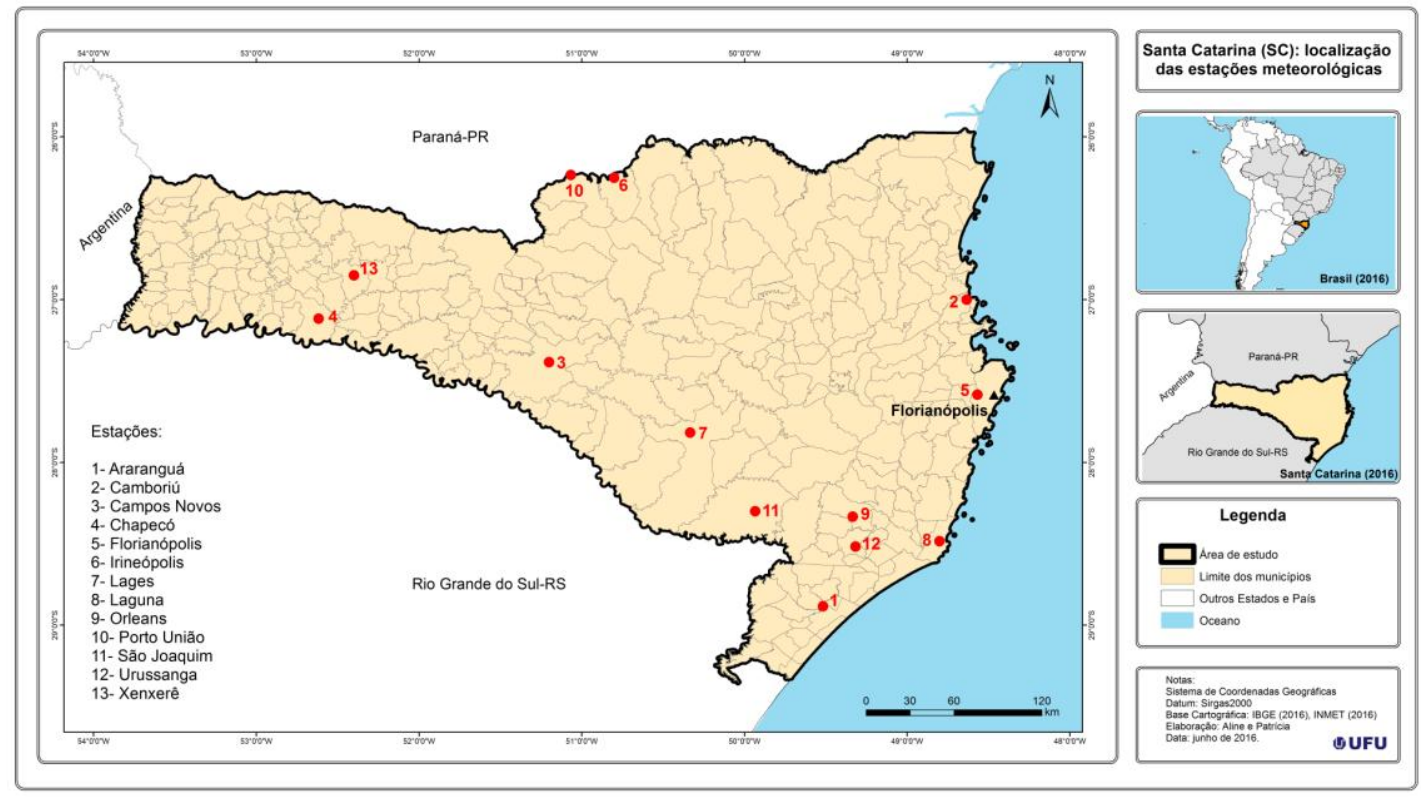

Figura 2 - Espacialização das estações meteorológicas adotadas no estudo. Elaboração: autores, 2016.

A partir das estações selecionadas, foi feito o tratamento e a organização dos dados utilizados para o cálculo do balanço hídrico, com base nos valores de temperatura e precipitação pluviométrica, compreendendo o período entre 1961 e 1990, ou seja, um total de 30 anos. Para calcular o balanço hídrico foi utilizada a metodologia proposta por Thornthwaite e Mather (1955), com a Capacidade de água 
disponível no solo (CAD) de $100 \mathrm{~mm}$, como valor padrão. Para efetuar os cálculos foi utilizada uma planilha eletrônica elaborada por Rollin e Sentelhas (1999).

Dessa forma, primeiramente foi feito o balanço hídrico de todos os anos da série histórica adotada (19611990) para as 13 estações e em seguida foram feitos os balanços hídricos de acordo com as projeções adotadas para o ano de 2080 com as alterações incluídas nos quadro 1.

Quadro 1 - Projeções para 2080, inseridas nos intervalos apontados pelo IPCC (2007)

\begin{tabular}{|l|l|}
\hline Temperatura & Aumento de $4^{\circ} \mathrm{C}$ para todos os meses do ano. \\
\hline \multirow{2}{*}{ Precipitação Pluviométrica } & Aumento das chuvas no período dezembro/janeiro/fevereiro em 5\%. \\
\cline { 2 - 2 } & Redução das chuvas no período junho/julho/agosto em $10 \%$. \\
\hline
\end{tabular}

Fonte: Adaptado do IPCC, 2007. Elaboração: autores, 2016.

\section{RESULTADOS E DISCUSSÕES}

Para a estação do município de Araranguá, nota-se no balanço hídrico de 1961-1990 um déficit hídrico no mês de janeiro e reposição nos meses de fevereiro e março. Já o mês de abril é caracterizado pela retirada de água no solo e novamente a ocorrência de déficit hídrico. Maio e junho caracterizam-se pela reposição de água no solo, fazendo com que nos meses subsequentes (julho, agosto, setembro, outubro e novembro) haja excedente hídrico. Já o mês de dezembro é caracterizado pela retirada de água no solo e consequentemente a ocorrência de déficit hídrico.

A partir da projeção para o ano de 2080, nota-se na mesma estação um outro cenário, onde o período correspondente de janeiro a maio é caracterizado pelo predomínio de déficit hídrico, os meses de junho, julho e agosto por uma reposição de água no solo. Em agosto inicia-se os excedentes hídricos, registrando os mesmos até o mês de outubro. Em novembro e dezembro começa haver registros de retirada de água no solo e consequentemente déficit hídrico. (Figura 3).
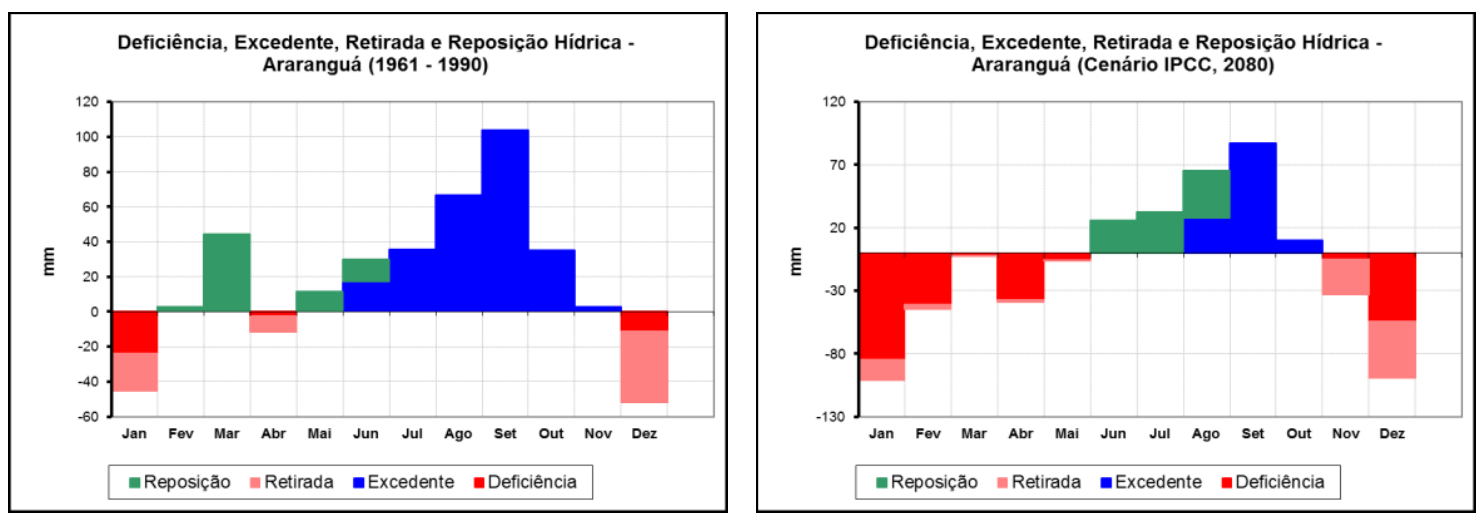

Figura 3 - Balanço hídrico 1961-1990 e cenário para 2080 - Araranguá/SC

Fonte dos dados: INMET, 2016. 
XVII Simpósio Brasileiro de Geografia Fisica Aplicada

I Congresso Nacional de Geografia Física
OS DESAFIOS DA GEOGRAFIA FÍSICA NA FRONTEIRA DO CONHECIMENTO

Instituto de Geociências - Unicamp

Campinas - SP

28 de Junho à 02 de Julho de 2017

Elaboração: autores, 2016.

Nota-se na estação do município de Camboriú entre os anos de 1961 e 1990 a ocorrência de excedente hídrico em todos os meses do ano, mas principalmente em fevereiro que chegou a $80 \mathrm{~mm}$ e em julho que ultrapassou os $100 \mathrm{~mm}$ de água disponível no solo. Já no balanço hídrico com as projeções para 2080 verifica-se algumas alterações significativas, sendo que no mês de março começa haver retirada de água e um pouco de déficit hídrico e os meses de abril e maio reposição hídrica. Observa-se, nesse cenário futuro, a redução dos valores de excedente em todos os meses em que o mesmo foi verificado de 1961-1990 (Figura 4).
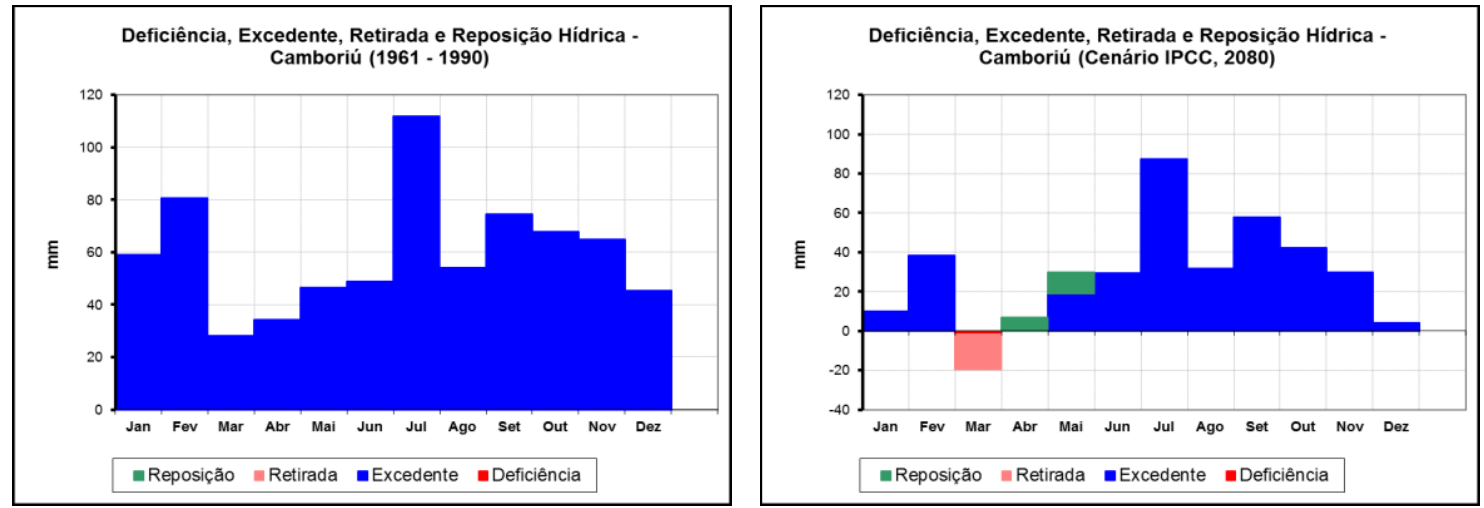

Figura 4 - Balanço hídrico 1961-1990 e cenário para 2080 - Camboriú/SC Fonte dos dados: INMET, 2016.

Elaboração: autores, 2016.

O município de Campos Novos é caracterizado pela ocorrência de excendente hídrico em todos os meses do ano em ambos os cenários, ou seja, tanto no de 1961-1990, quanto nas projeções para 2080. No entanto, mesmo com a continuidade de excedente hídrico na projeção de 2080, nota-se que em quase todos os meses haverá redução dos valores dos excendetes, como pode ser observado no mês de julho em que o valor ultrapassava os $140 \mathrm{~mm}$ e passa a ser menor que $120 \mathrm{~mm}$ no cenário futuro. (Figura 5).
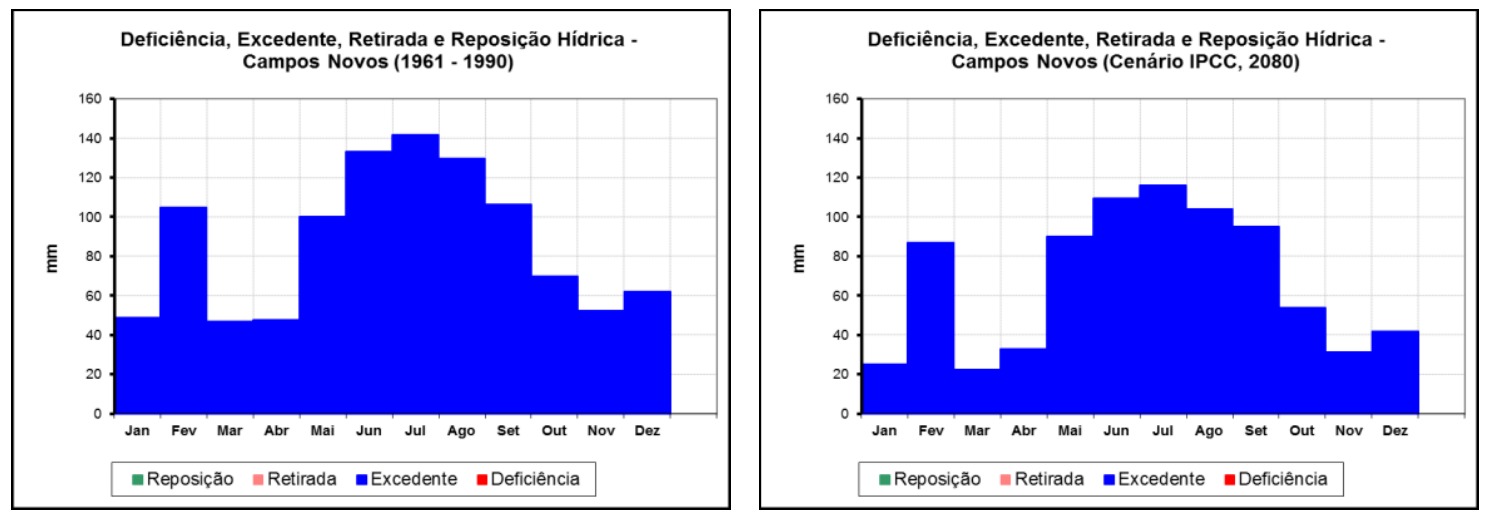

Figura 5 - Balanço hídrico 1961-1990 e cenário para 2080 - Campos Novos/SC

Fonte dos dados: INMET, 2016.

Elaboração: autores, 2016. 
Em Chapecó é possível observar no balanço hídrico de 1961 a 1990 o registro de excedente hídrico em todos os meses do ano, com maior valor registrado em julho, o qual foi superior a $100 \mathrm{~mm}$. Já no balanço hídrico com as projeções para 2080, nota-se algumas mudanças significativas, como por exemplo o mês de janeiro quando é registrado retirada de água no solo e como consequência o déficit hídrico. Em fevereiro haverá reposição e novamente excedente hídrico. Em março haverá retirada e déficit hídrico e, por fim, abril e maio terá reposição e um retorno do excedente hídrico até o mês de dezembro (Figura 6).
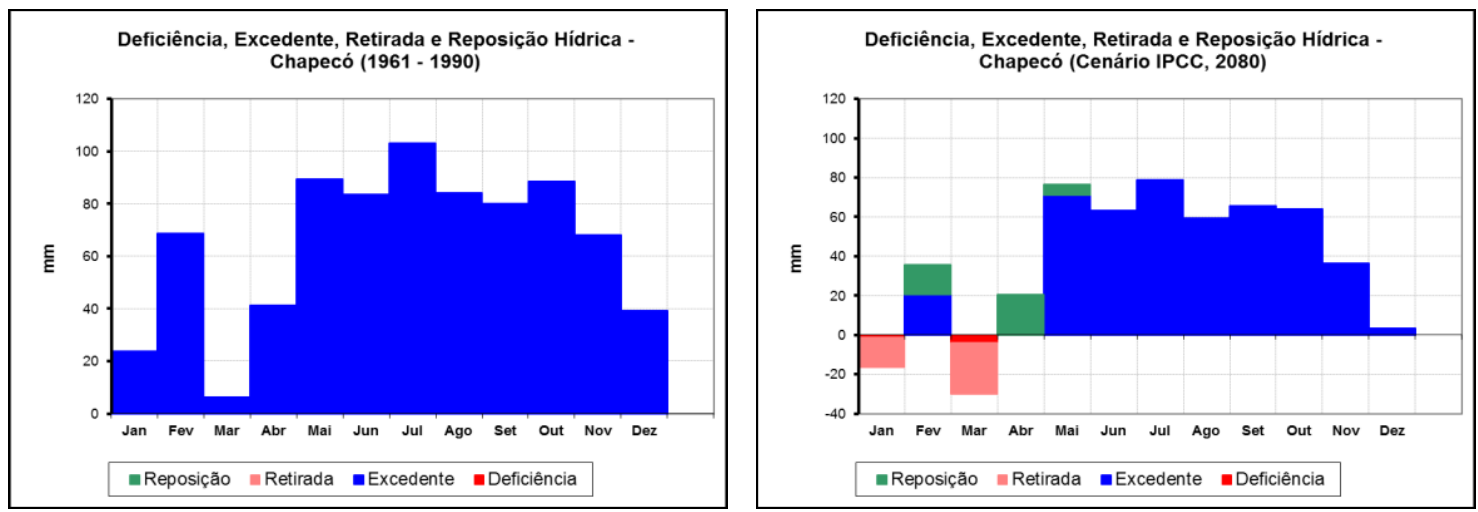

Figura 6 - Balanço hídrico 1961-1990 e cenário para 2080 - Chapecó/SC.

Fonte dos dados: INMET, 2016.

Elaboração: autores, 2016.

Para a estação do município de Florianópolis é possível observar no cálculo do balanço hídrico de 1961 a 1990 que todos os meses ao longo do ano registram apenas excedentes hídricos, ressaltando principalmente fevereiro e setembro, os quais são responsáveis pelos maiores valores. Quanto ao balanço hídrico para o cenário de 2080, notam-se algumas alterações no padrão de disponibilidade hídrica, uma vez que janeiro apresentará retirada e déficit hídrico, fevereiro e março reposição de água no solo, abril novamente com retirada e déficit, maio com reposição fazendo com que os meses entre junho e novembro registrem excedente e dezembro com retirada e déficit hídrico (Figura 7).
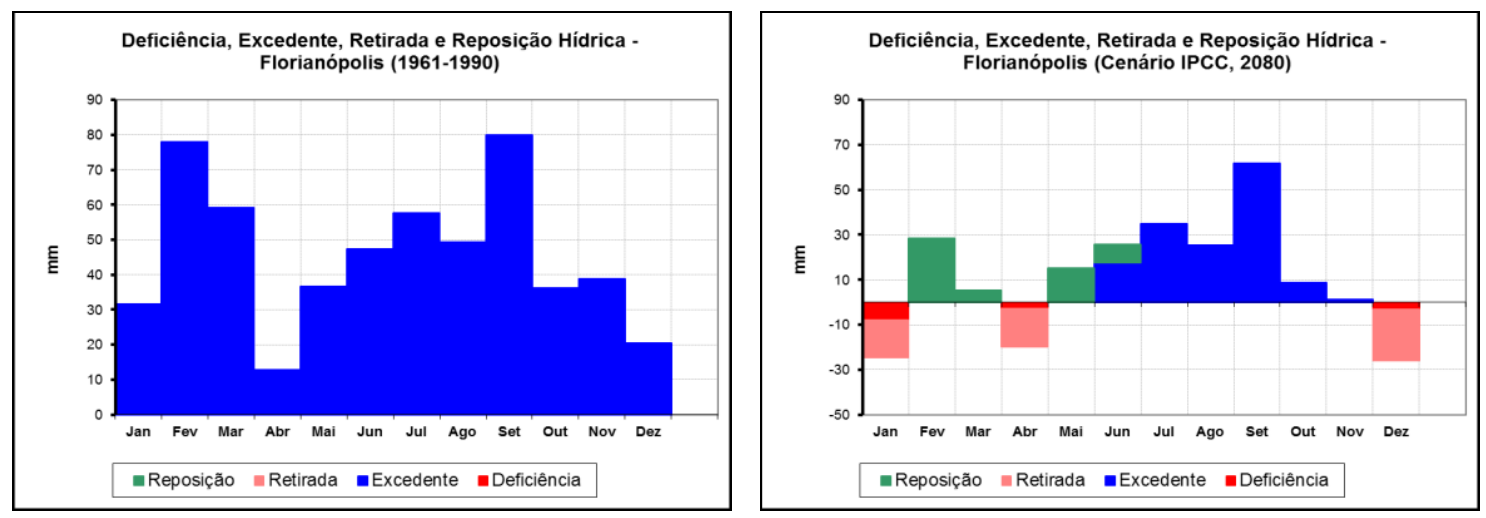

Figura 7 - Balanço hídrico 1961-1990 e cenário para 2080 - Florianópolis/SC.

Fonte dos dados: INMET, 2016.

Elaboração: autores, 2016. 
O município de Irineópolis apresenta apenas excedentes hídricos em ambas as situações. Porém é possível observar que haverá redução nos valores dos excedentes em todos os meses do ano, fato que pode ser notado principalmente no mês de julho, mês este que apresentava excedente superior a $110 \mathrm{~mm}$ e na projeção para 2080 passa a ter valor inferior a $100 \mathrm{~mm}$ (Figura 8).
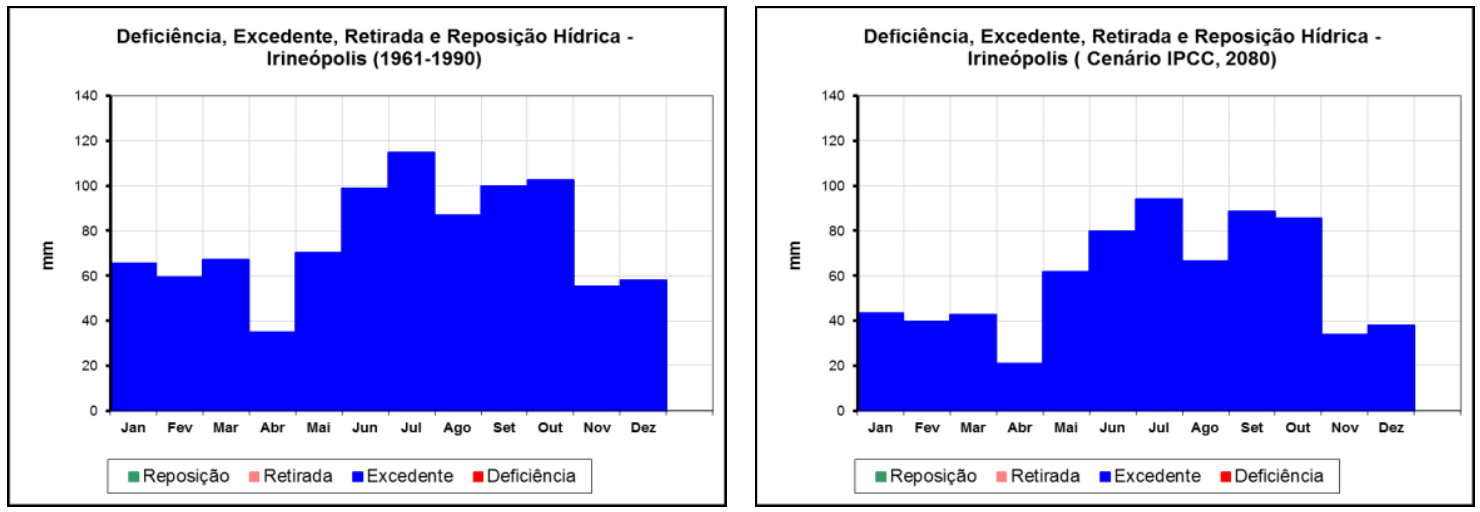

Figura 8 - Balanço hídrico 1961-1990 e cenário para 2080 - Irineópolis/SC

Fonte dos dados: INMET, 2016.

Elaboração: autores, 2016.

Assim como no município de Irineópolis, em Lages foram registradas ocorrências de excedentes durante todo ano, tanto no balanço hídrico de 1961-1990, quanto na projeção do IPCC para 2080. Porém, mesmo com a permanência do excedente é também possível verificar redução nos seus valores ao longo dos meses, como, por exemplo, o mês de agosto que apresentava quase $100 \mathrm{~mm}$ de excedente, passando a ter na projeção para 2080, um valor inferior a 80 mm (Figura 9).
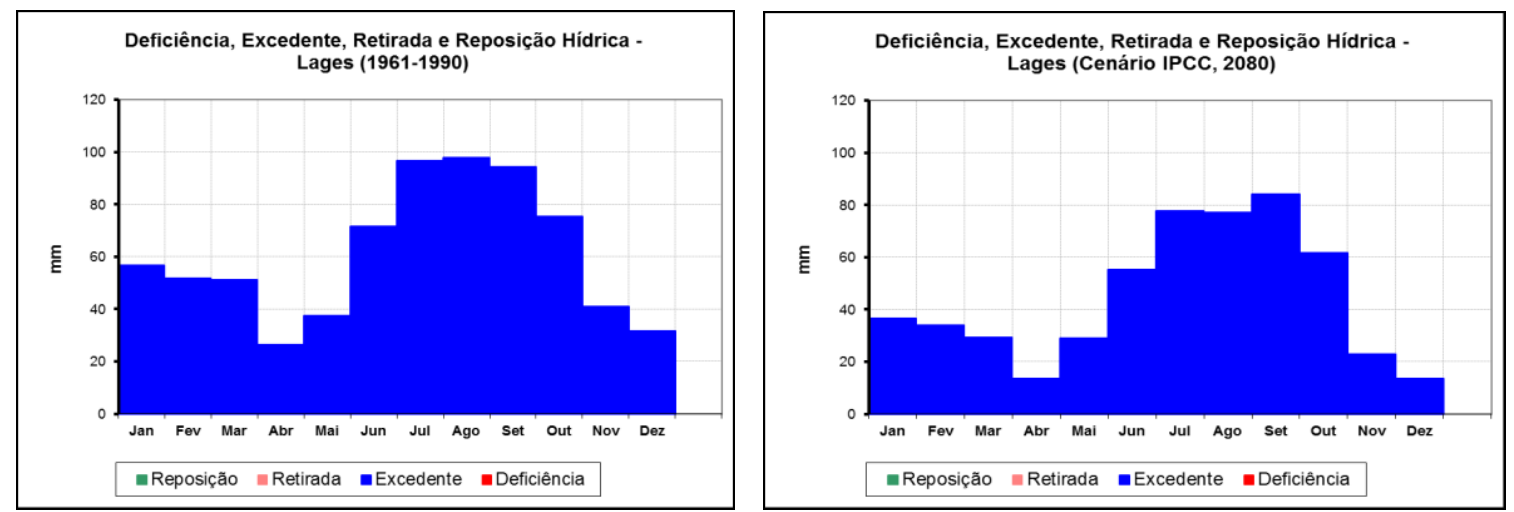

Figura 9 - Balanço hídrico 1961-1990 e cenário para 2080 - Lages/SC.

Fonte dos dados: INMET, 2016.

Elaboração: autores, 2016.

Para a estação do município de Laguna, é possível verificar no balanço hídrico de 1961 a 1990 que o mês de janeiro apresenta retirada de água no solo e também a presença de déficit hídrico. Os meses de fevereiro e março, reposição e de abril a novembro a ocorrência apenas de excedentes hídricos, sendo o 
máximo registrado no mês de agosto. Em dezembro há novamente o registro de retirada e de déficit hídrico.

Já no balanço hídrico para 2080 observa-se algumas alterações, como por exemplo, os meses de janeiro a abril que registraram apenas retirada e déficit hídrico. Maio, junho e julho terão reposição de água no solo. Agosto, setembro e outubro terão excedente hídrico e, por fim, novembro e dezembro terão retirada e déficit hídrico (Figura 10).
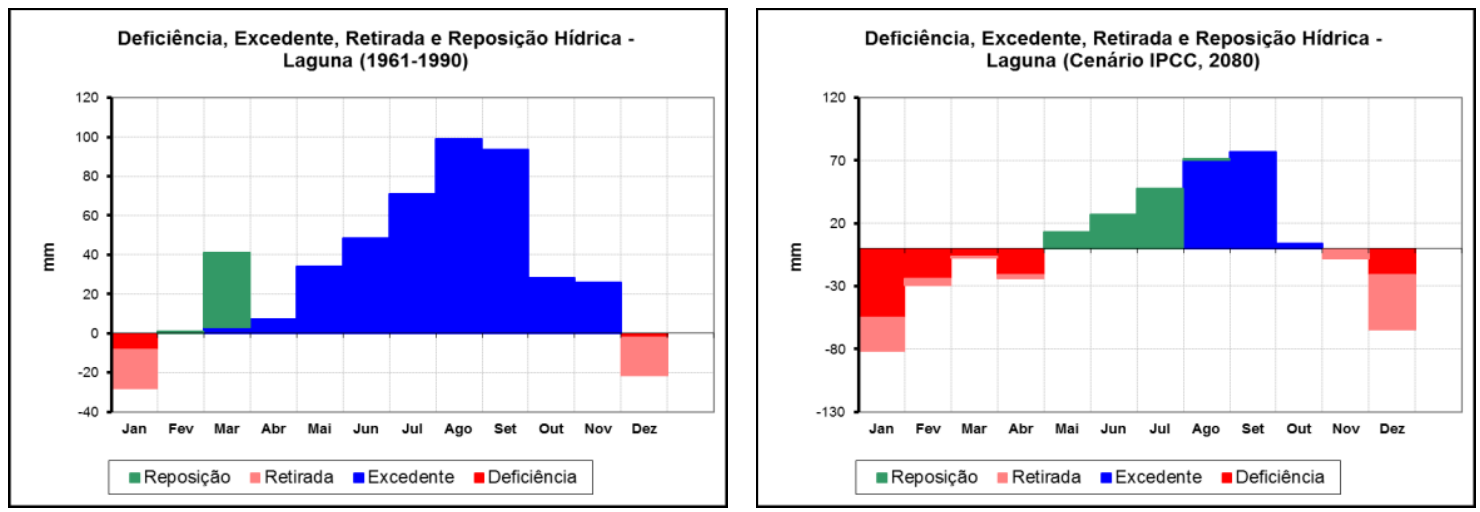

Figura 10 - Balanço hídrico 1961-1990 e cenário para 2080 - Laguna/SC.

Fonte dos dados: INMET, 2016.

Elaboração: autores, 2016.

Na estação do município de Orleans é possível notar que houve mudanças nos padrões da disponibilidade hídrica, uma vez que no balanço hídrico de 1961-1990 ocorreram apenas registros de excedente hídrico, destacando-se o mês de setembro que ultrapassou os $100 \mathrm{~mm}$ de água disponível no solo. Já no balanço hídrico para o cenário de 2080, observa-se que em janeiro e fevereiro ocorrerão reposições de água e registro de excedente até o mês de março. Em abril haverá retirada de água e presença de déficit hídrico. De junho a outubro o que predominará serão os excedentes hídricos e novembro e dezembro retirada de água e déficit hídrico (Figura 11).
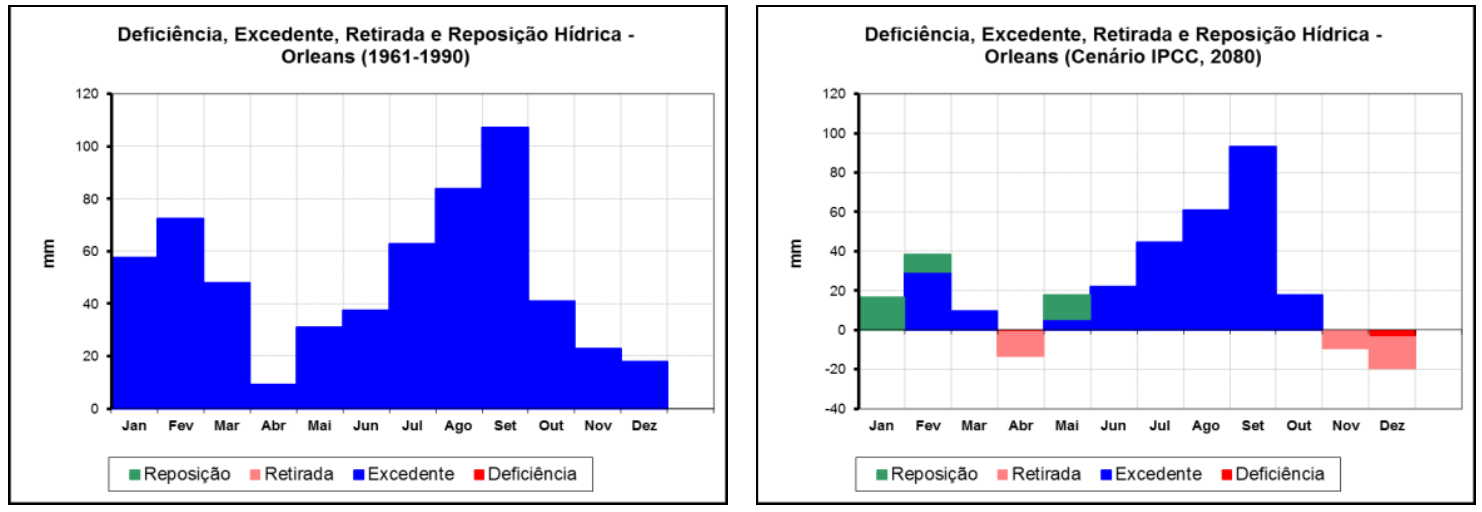

Figura 11 - Balanço hídrico 1961-1990 e cenário para 2080 - Orleans/SC.

Fonte dos dados: INMET, 2016.

Elaboração: autores, 2016. 
Em Porto União verifica-se a ocorrência apenas de excedentes hídricos em ambas as situações analisadas. O que ocorrerá de mudanças será a diminuição dos valores dos excedentes em todos os meses do ano, como por exemplo, o mês de julho que de 1961 a 1990 registrou excedente hídrico superior a 115 mm e passa a ter um valor inferior a $100 \mathrm{~mm}$ no balanço hídrico com as projeções para 2080 (Figura 12).
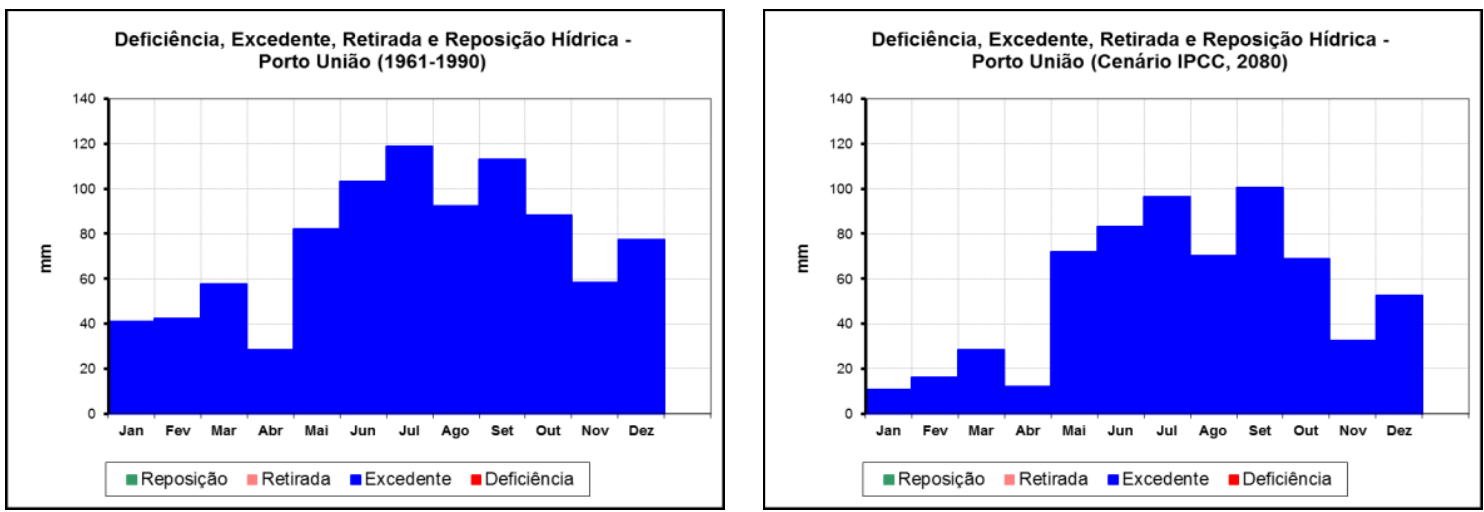

Figura 12 - Balanço hídrico 1961-1990 e cenário para 2080 - Porto União/SC.

Fonte dos dados: INMET, 2016.

Elaboração: autores, 2016.

Assim como em Porto União, a estação do município de São Joaquim também registrou apenas excedentes hídricos nos dois cenários, ou seja, tanto no balanço hídrico de 1961 a 1990, quanto no das projeções para 2080. No entanto, em todos os meses do ano no balanço hídrico com as projeções há queda nos valores dos excedentes, como por exemplo, nos meses de agosto e setembro que registram valores superiores a 130 mm e passarão a registrar valores menores no balanço hídrico (Figura 13).
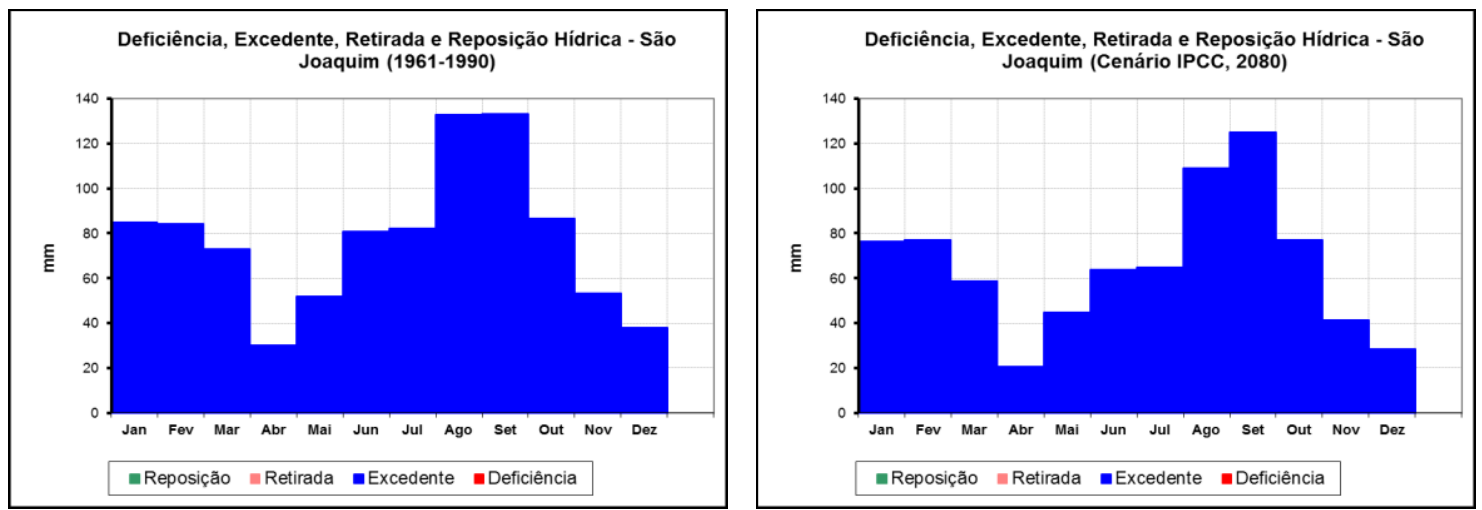

Figura 13 - Balanço hídrico 1961-1990 e cenário para 2080 - São Joaquim/SC.

Fonte dos dados: INMET, 2016.

Elaboração: autores, 2016.

Também em Urussanga é possível verificar no balanço hídrico de 1961 a 1990 que em todos os meses ao longo do ano são registrados excedentes hídricos. Vale destacar os meses de agosto e de setembro que os valores ultrapassam os $100 \mathrm{~mm}$ de excedente. Já no balanço hídrico com as projeções para 2080, pode-se notar algumas mudanças no padrão de disponibilidade de água no solo ao longo do ano. O mês de janeiro 
passa a ser responsável pela reposição de água. Em fevereiro e março ocorrerão excedentes hídricos. Em abril haverá retirada de água, maio reposição e de junho até outubro haverá excedente hídrico. Por fim, os meses de novembro e dezembro registrarão retirada de água no solo e, consequentemente, déficit hídrico (Figura 14).
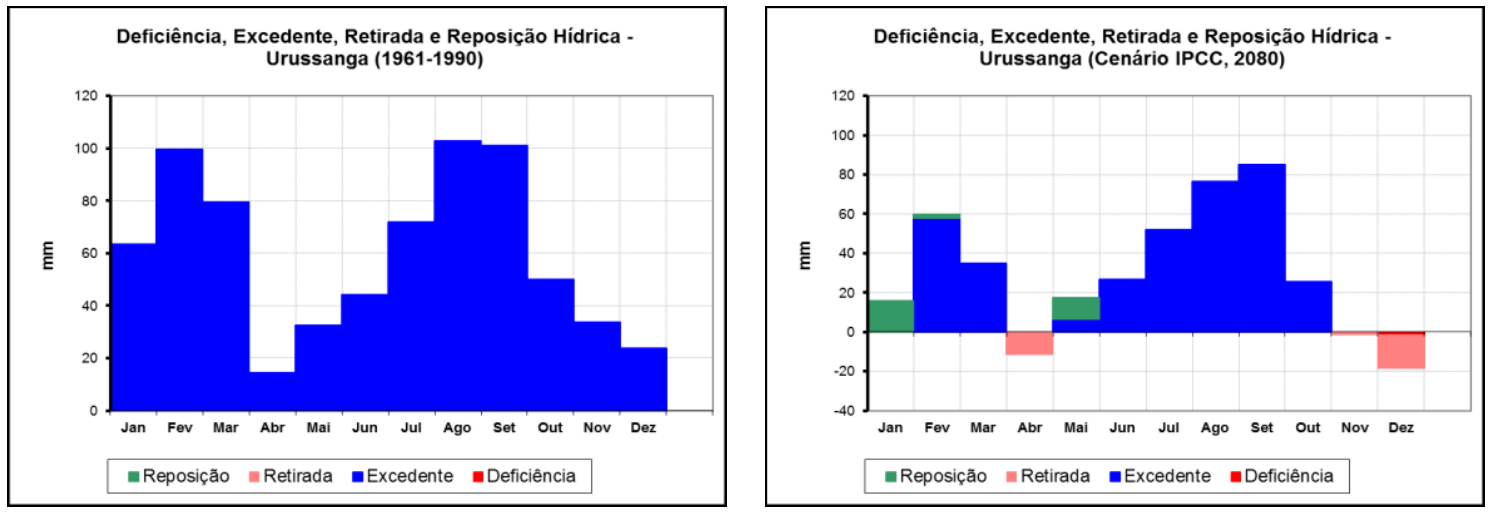

Figura 14 - Balanço hídrico 1961-1990 e cenário para 2080 - Urussanga/SC.

Fonte dos dados: INMET, 2016.

Elaboração: autores, 2016.

Por fim, na estação do município de Xenxerê podemos notar que ambos os balanços hídricos calculados registraram excedentes hídricos, conforme pode ser visualizado na figura 15.
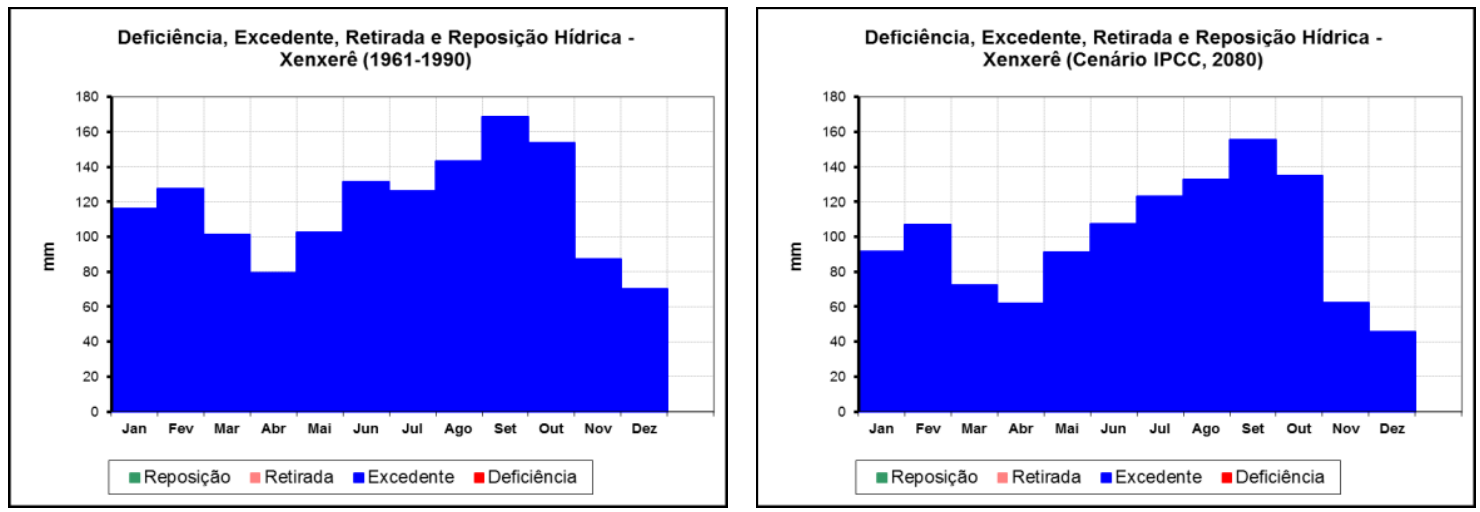

Figura 15 - Balanço hídrico 1961-1990 e cenário IPCC para 2080 - Xenxerê/SC.

Fonte: INMET, 2016.

Elaboração: autores, 2016.

Algumas alterações podem ser observadas no padrão de disponibilidade hídrica no solo desse município, uma vez que em todos os meses do ano ocorrerá diminuição dos valores dos excedentes hídricos quando comparamos o balanço hídrico de 1961 a 1990 e o das projeções para 2080, fato esse pode ser observado no mês de setembro que de 1961 a 1990 registra excedente superior a $168 \mathrm{~mm}$, passando a ter $155 \mathrm{~mm}$ no balanço hídrico com as projeções para 2080. 


\section{CONSIDERAÇÕES FINAIS}

Com a realização desse trabalho foi possível verificar que em todas as estações selecionadas haverá mudanças no padrão de disponibilidade hídrica do solo no estado de Santa Catarina, ou seja, localidades que no período de 1961 a 1990 apresentam apenas ocorrências de excedentes hídricos, nas projeções para 2080 passarão a registrar também retirada de água do solo e consequentemente déficit hídrico. Algumas localidades permanecerão com registros de excedentes hídricos em todos os meses, porém foi possível notar alterações significativas e impactantes em seus valores. Cenários diferenciados ocorrerão em função das características climáticas atuais de cada localidade, bem como efeitos combinados dos fatores fisiográficos controladores do ritmo climático no território estudado.

Por fim, cabe salientar a importância de estudos de cenários no âmbito das mudanças climáticas globais. É importante entender como estas irão influenciar na dinâmica do planeta, ou seja, seus impactos sobre os ecossistemas, sobre as atividades humanas, enfim, nas diversas situações de relações entre homem e natureza nas diversas escalas de espaço e de tempo.

\section{REFERÊNCIAS}

$=\mathrm{j} \& \mathrm{q}=\&$ esrc $=\mathrm{s} \&$ source $=$ web $\& \mathrm{~cd}=4 \& \mathrm{cad}=\mathrm{rja} \& u a c t=8 \& \mathrm{ved}=0$ ahUKEwiQodTGwdbSAhXLFpAKHaNdCtUQFggy MAM\&url=http\%3A\%2F\%2Fwww.cbmet.com\%2Fcbm-files\%2F22d6e61e791f3aef0808eddcecd59d09dd.doc\&usg=AFQjCNE_HiqxIxErkUkGBj68277ayrpcw\&sig2=pEwxdq8zXeolroPd4btY1Q> Acesso em junho de 2016. D’ ANGIOLELLA, G; SILVA, J. F. Balanço Hídrico climatológico do Brasil.[S.1],[200-].Disponível em: < DENARDIN, V. F; SUlZBACH, M. T. A Agropecuária no Oeste Catarinense-SC: É possível ser sustentável? Disponível em: <http://www.ecoeco.org.br/conteudo/publicacoes/encontros/v_en/Mesa4/5.pdf〉. Acesso em 15 de junho de 2016.

FERREIRA, V. O; Silva, G. A; SILVA, R. E; FRASSON, V. M. Avaliação de cenário de mudança climática para o ano de 2080 (IPCC, 2007) para a bacia do Rio Grande, no Sudeste Brasileiro. In: XXI Simpósio Brasileiro de Recursos Hídricos, 2015, Brasília. Anais do XXI Simpósio Brasileiro de Recursos Hídricos. Porto Alegre: ABRH, 2015. v. 1. p. 01-09.

INSTITUTO BRASILEIRO DE GEOGRAFIA E ESTATÍSTICA (IBGE), Santa Catarina. Disponível em: $<$ http://cidades.ibge. gov.br/xtras/uf.php?coduf=42>. Acesso em 15 de junho de 2016.

INSTITUTO NACIONAL DE METEOROLOGIA. Disponível em:<http://www.inmet.gov.br/html/agro.html>. Acesso em 15 de junho de 2016.

NOBRE, C. A; YOUNG, A. F.. Vulnerabilidades das megacidades brasileiras às mudanças climáticas: região metropolitana de São Paulo, Relatório Final. São Paulo, 2011.

PORTAL DA ECONOMIA DE SANTA CATARINA. Economia Catarinense. Disponível em: <http://novosite.fepese.org.br/portaldeeconomia-sc/index.php?c=economia\#_Toc346963828>. Acesso em 15 de junho de 2016.

Relatório do IPCC/ONU - Novos Cenários Climáticos - Versão em português: iniciativa da Ecolatina 2. Conferência Latino Americana sobre meio ambiente e responsabilidade social. Paris, 2007. Disponível em: < http://fmclimaticas.org.br/wp-content/uploads/2014/03/IPCC-contribui_es-do-G.-I-ao-4-relat_rio-A-base-daCiencia-F_sica.pdf> Acesso em junho de 2016. 


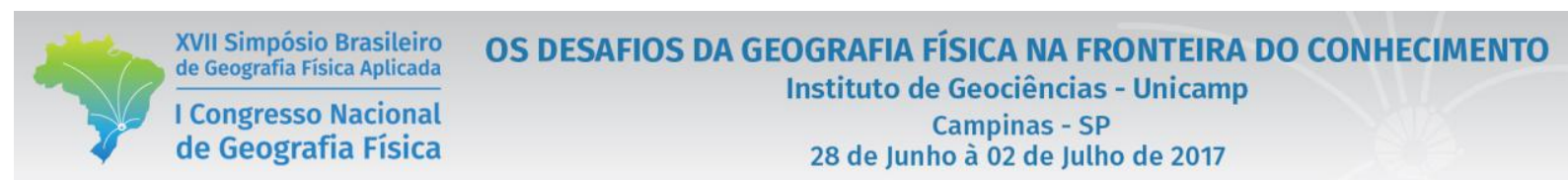

ROLLIM, G. S. \& SENTELHAS, P. C. Balanço hídrico normal por Thorntwaite e Mather (1955). Piracicaba: ESALQ/USP - Departamento de Ciências Exatas: Área de Física e Meteorologia, 1999.

SEBRAE. Santa Catarina números. em Disponível <http://www.sebrae.com.br/Sebrae/Portal\%20Sebrae/Anexos/Relatorio\%20Estadual.pdf $>$. Acesso em 15 de junho de 2016.

SENTElHAS, P. C.; ANGElOCCI, L. R. Meteorologia Agrícola: Balanço Hídrico Climatológico Normal e Sequencial, de Cultura e para Manejo da Irrigação. Disponível em: <http://www.lce.esalq.usp.br/aulas/lce306/Aula9.pdf>. Acesso em 15 de junho de 2016.

ThORNThwaite, C. W.; MATHER, J. R. The water balance. Publications in Climatology. New Jersey, Drexel Institute of Technology, 104p. 1955. 